This document was prepared as an account of work sponsored by the United States Government. While this document is believed to contain correct information, neither the United States Government nor any agency thereof, nor the Regents of the University of California, nor any of their employees, makes any warranty, express or implied, or assumes any legal responsibility for the accuracy, completeness, or usefulness of any information, apparatus, product, or process disclosed, or represents that its use would not infringe privately owned rights. Reference herein to any specific commercial product, process, or service by its trade name, trademark, manufacturer, or otherwise, does not necessarily constitute or imply its endorsement, recommendation, or favoring by the United States Government or any agency thereof, or the Regents of the University of California. The views and opinions of authors expressed herein do not necessarily state or reflect those of the United States Government or any agency thereof or the Regents of the University of California.

This is a preprint of an article published in Chemical Communications. The final published communication is available online at: http://pubs.rsc.org/en/Content/ArticleLanding/2011/CC/c1cc11329a

\title{
Uranyl sequestration: synthesis and structural characterization of uranyl complexes with a tetradentate methylterephthalamide ligand ${ }^{1}$
}

\author{
Chengbao Ni, ${ }^{a}$ David K. Shuh, ${ }^{a}$ Kenneth N. Raymond ${ }^{\mathrm{a}, \mathrm{b}_{*}}$
}

Uranyl complexes of a bis(methylterephthalamide) ligand $\left(\mathrm{LH}_{4}\right)$ have been synthesized and characterized by $\mathrm{X}$-ray crystallography. The structure is an unexpected $\left[\mathrm{Me}_{4} \mathrm{~N}\right]_{8}\left[\mathrm{~L}\left(\mathrm{UO}_{2}\right)\right]_{4}$ tetramer, formed via coordination of the two MeTAM units of $L$ to two uranyl moieties. Addition of $\mathrm{KOH}$ to the tetramer gave the corresponding monomeric uranyl methoxide species $\left[\mathrm{Me}_{4} \mathrm{~N}\right] \mathrm{K}_{2}\left[\mathrm{LUO}_{2}(\mathrm{OMe})\right]$.

The uranyl ion $\left(\mathrm{UO}_{2}{ }^{2+}\right)$ is the most common species for uranium under oxidizing conditions and in vivo. ${ }^{2-4}$ During the past few decades, various approaches have been used to the design of uranyl-selective chelators: several multidentate ligands based on phosphonic ligands, ${ }^{5-8}$ siderophore-based units (Scheme 1$),{ }^{9}$ or a combination of both ${ }^{5-11}$ have been identified as effective. Studies by Durbin, Raymond, and coworkers have evaluated the efficacy of multidentate ligands containing catechol derivatives, 3hydroxy- $N$-methyl-2-(1H)-pyridinone (Me-3,2-HOPO), and 1hydroxypyridin-2-one (1,2-HOPO) binding units. Several of these ligands are orally active decorporation agents and effective in reducing $\mathrm{UO}_{2}{ }^{2+}$ in both kidneys and skeleton (removal efficiency in the sequence MeTAM $>\operatorname{CAM}(\mathrm{S})>\mathrm{CAM}(\mathrm{C})>\mathrm{Me}-$ 3,2-HOPO > 1,2-HOPO). ${ }^{9}$ 12-14 Of the ligands evaluated, the 5LiO-(Me-3,2-HOPO) and 5Li-CAM(S) ligands were identified as low or non-toxic ligands with high efficiency. ${ }^{14}$ Subsequently, tetradentate bis-Me-3,2-HOPO ligands for uranyl sequestration have been intensely studied. ${ }^{15-18}$ It has been shown that $2 \mathrm{Li}$ (such as ethylene and thiophene) linked ligands ${ }^{15-17}$ exhibit the most planar coordination mode about $\mathrm{UO}_{2}{ }^{2+}$ and that the $4 \mathrm{Li}$ ligand binds the most strongly to $\mathrm{UO}_{2}{ }^{2+}$ in all bis-Me-3,2-HOPO ligands. ${ }^{18}$ Pellet-Rostaing and coworkers have reported uranyl sequestration studies of a series of water soluble five-carbon linked bis-CAM(S) ligands ${ }^{10}$ as well as calixarene ligands incorporating two CAM(S) or 1,2-HOPO units. ${ }^{11}$ They showed that the efficiency of the bis-CAM(S) ligands depends on the rigidity and steric hindrance of the spacers and that the combination of calixarene and $\mathrm{CAM}(\mathrm{S})$ or 1,2-HOPO features different uranyl affinities at different $\mathrm{pH} .{ }^{10,11}$

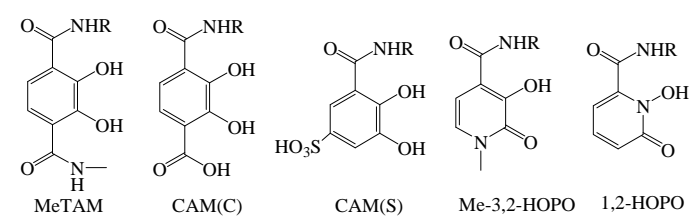

Scheme 1 Siderophore-based binding units.

Despite the fact that the MeTAM unit binds more strongly to $\mathrm{UO}_{2}{ }^{2+}$ than $\mathrm{CAM}(\mathrm{S})$ or HOPO, ${ }^{9}$ uranyl sequestration studies with MeTAM ligands have attracted less attention, due primarily to the very severe toxicity associated with the earlier 3Li-(MeTAM) and 4Li-(MeTAM) ligands. ${ }^{14}$ In addition, the diprotic nature of MeTAM gives the corresponding uranyl complex -2 (or more) charge, which greatly complicates the crystallization process for structural analysis. Given these issues, the strong binding affinity of MeTAM makes this class of ligands attractive for nuclear waste remediation. Due to the low-toxicity and improved solubility of the $5 \mathrm{LiO}$ backbone as shown by previous studies with the 5LiO-(Me-3,2-HOPO) ligand, ${ }^{14}$ we prepared the MeTAM analog 5LiO-(MeTAM) ( $\mathbf{L H}_{4}$, Scheme 2) to study the structures of its uranyl complexes. Herein, we describe the synthesis and characterization of the uranyl complexes with $\mathbf{L}$. Xray crystallography has revealed that $\left[\mathbf{L U O}_{2}\right]^{2-}$ forms an unexpected tetramer $\left[\mathbf{L}\left(\mathrm{UO}_{2}\right)\right]_{4}{ }^{8-}$, in which the two MeTAM units of each $\mathbf{L}$ bind to two $\mathrm{UO}_{2}{ }^{2+}$ ions. The addition of $\mathrm{KOH}$ changes the preferred coordination nature of the tetramer to give the corresponding uranyl methoxide species $\left[\mathrm{LUO}_{2}(\mathrm{OMe})\right]^{3-}$ with the two MeTAM units of $\mathbf{L}$ binding to the same uranyl moiety.

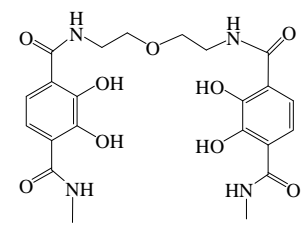

Scheme 2. The 5LiO-(MeTAM) ligand $\left(\mathbf{L H}_{4}\right)$. 
The uranyl complex $\left[\mathrm{Et}_{3} \mathrm{NH}\right]_{2}\left[\mathbf{L U O}_{2}\right] \cdot 2 \mathrm{H}_{2} \mathrm{O}$ was prepared by reaction of $\mathrm{UO}_{2}\left(\mathrm{NO}_{3}\right)_{2} \cdot 6 \mathrm{H}_{2} \mathrm{O}$ with $\mathbf{L H}_{4}$ in the presence of a slight excess of $\mathrm{Et}_{3} \mathrm{~N}$ and isolated as a brown solid. $\dagger$ $\left[\mathrm{Et}_{3} \mathrm{NH}\right]_{2}\left[\mathbf{L U O}_{2}\right] \cdot 2 \mathrm{H}_{2} \mathrm{O}$ is highly soluble in $\mathrm{MeOH}$ or $\mathrm{H}_{2} \mathrm{O}$. Attempts to crystallize the complex as the $\left[\mathrm{Et}_{3} \mathrm{NH}\right]^{+}$salt from various solvents were unsuccessful. By replacing $\left[\mathrm{Et}_{3} \mathrm{NH}\right]^{+}$with $\mathrm{Me}_{4} \mathrm{~N}^{+}$, red crystals readily formed with slow diffusion of $\mathrm{Et}_{2} \mathrm{O}$ into a MeOH/DMF (50:1) solution of the uranyl complex.

The solid state structure of $\left[\mathrm{LUO}_{2}\right]^{2-}$ is a tetramer (Fig.1); $\left[\mathrm{Me}_{4} \mathrm{~N}\right]_{8}\left[\mathbf{L}\left(\mathrm{UO}_{2}\right)\right]_{4}$ crystallizes in space group $\mathrm{I}_{1} /$ acd with a large unit cell ( $\left.\mathrm{ca} .42,300 \AA^{3}\right)$. There is one $\left[\mathbf{L}\left(\mathrm{UO}_{2}\right)\right]^{2-}$ moiety in the asymmetric unit and there are eight tetramers in the unit cell. $\dagger$ As shown in Fig. 1, $\left[\mathbf{L}\left(\mathrm{UO}_{2}\right)\right]_{4}{ }^{8-}$ has a helical structure, in which the ligands adopt a bridging coordination mode with two TAM units in each $\mathbf{L}$ coordinated to two uranyl ions. Uranyl complexes in which the bis-CAM or bis-Me-3,2-HOPO ligands show a bridging coordination mode have been reported; however, this has only been observed in ligands with either very rigid backbones ${ }^{17,} 19$ or very long linker lengths. ${ }^{16}$ Considering the moderate length and high flexibility of the $5 \mathrm{LiO}$ backbone and the fact that the closely related 5Li-(Me-3,2-HOPO) ligand forms a monomeric uranyl complex, ${ }^{15}$ the bridging coordination of $\mathbf{L}$ in $\left[\mathbf{L}\left(\mathrm{UO}_{2}\right)\right]_{4}{ }^{8-}$ is surprising. The fifth position of the uranyl ions in the tetramer is occupied by an amide oxygen atom, due probably to ligand distortion which brings the amide oxygen atom in the vicinity of the uranyl ion.

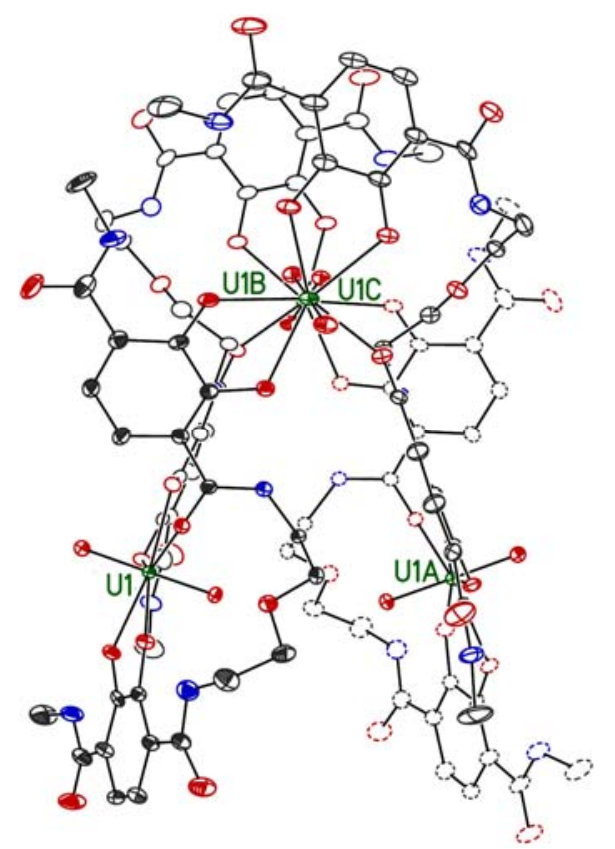

Fig. 1. Crystal structure of $\left[\mathrm{LUO}_{2}\right]_{4}{ }^{8-}$ (30\% probability) without hydrogen atoms. The four ligands are presented in four different ellipsoid formats. Carbon atoms are grey, nitrogen atoms blue, oxygen atoms red, and uranium atoms green.

In $\left[\mathbf{L}\left(\mathrm{UO}_{2}\right)\right]_{4}{ }^{8-}$, the slightly lengthened $\mathrm{U}-\mathrm{O}(\mathrm{oxo})$ distances (1.785(5) and 1.794(6) $\AA$ ) than those in bis-Me-3,2HOPO or 1,2HOPO complexes ${ }^{16,17,20}$ are probably due to the presence of more negatively charged ligands. The $\mathrm{U}-\mathrm{O}_{\text {phenolate }}$ distances are in the range 2.342(6) to 2.397(5) $\AA$, comparable to the average U-O distance of $2.371(4) \quad \AA$ in $\mathrm{Na}_{4}[\mathrm{U}($ catechol $)] .^{21}$ A close examination of the structure revealed that the average $\mathrm{U}-\mathrm{O}_{\text {phenolate }}$ distances to the two MeTAM units are slightly different (2.345(6) $\AA$ and $2.380(5) \AA$ ) with the shorter $\mathrm{U}-\mathrm{O}_{\text {phenolate }}$ distance corresponding to the smaller torsion angle $\left(12.9(2)^{\circ}\right)$ between the MeTAM plane and the O-U-O plane. Thus, the bending of the MeTAM unit may lengthen the $\mathrm{U}-\mathrm{O}_{\text {phenolate }}$ distance slightly. The $\mathrm{U}-\mathrm{O}_{\text {amide }}$ distance of 2.365(5) $\AA$ in $\left[\mathbf{L}\left(\mathrm{UO}_{2}\right)\right]_{4}{ }^{8-}$ is similar to the U$\mathrm{O}_{\text {phenolate distances, indicating strong interactions between }}$ uranium and the amide oxygen. Such unusually strong interactions are precedented by those between the uranyl ion and a DMF or DMSO molecule occupying the fifth position of Me3,2-HOPO complexes. ${ }^{15}$ The average MeTAM bite angle is $66.4(2)^{\circ}$, close to those in $\mathrm{Na}_{4}\left[\mathrm{U}(\text { catechol) }]^{21}\right.$ and Me-3,2-HOPO uranyl complexes. ${ }^{15-17,20}$

The sum of the five equatorial O-U-O angles in $\left[\mathbf{L}\left(\mathrm{UO}_{2}\right)\right]_{4}{ }^{8-}$ is $360.5(2)^{\circ}$ and the mean deviation of the six equatorial atoms (five oxygens and one uranium) from the equatorial plane is 0.078(4) $\AA$, suggesting a good planar geometry around $\mathrm{UO}_{2}{ }^{2+}$. Unlike the monomeric bis-Me-3,2-HOPO uranyl complexes, in which the $\mathrm{O}_{\text {phenolate }}-\mathrm{U}-\mathrm{O}_{\text {phenolate }}$ angle can be viewed as a "ligand bite angle" and depends strongly on the linker length $\left(65.2(2)^{\circ}\right.$ to $\left.94.1(1)^{\circ}\right){ }^{16}$ there is no such angle in $\left[\mathbf{L}\left(\mathrm{UO}_{2}\right)\right]_{4}{ }^{8-}$. Thus, a comparison of this angle is not applicable. Instead, comparison of the remaining three angles to the average value of $75.7^{\circ}$, obtained by assuming each ligand (MeTAM or HOPO) bite angle approximately $66.5^{\circ}$, can be employed. $\dagger$ In a highly relaxed uranyl coordination environment, such as with untethered binding units, the remaining angles should be close to $75.7^{\circ}$, as is exactly the case in the untethered uranyl complex (Pr-Me-3,2-HOPO) ${ }_{2} \mathrm{UO}_{2}(\mathrm{DMF})$ with angles of $74.2(2), 76.8(2)$, and $76.1(2)^{\circ}$, respectively. ${ }^{15}$ In $\left[\mathbf{L}\left(\mathrm{UO}_{2}\right)\right]_{4}{ }^{8-}$, the corresponding angles of $76.0(2), 77.1(2)$, and $74.6(2)^{\circ}$ are within less than $1.5^{\circ}$ to the average value, suggesting an equally highly relaxed uranyl coordination environment. Thus, the bridging coordination of $\mathbf{L}$ and the tetramer formation are consequences of achieving a highly relaxed and planar geometry around $\mathrm{UO}_{2}{ }^{2+}$.

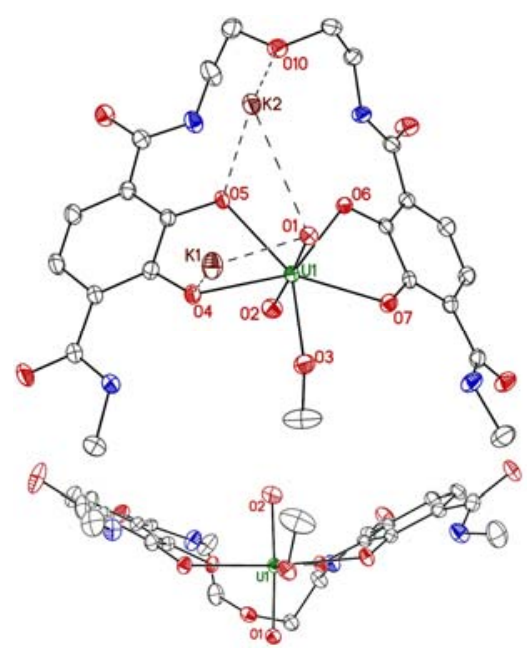

Fig. 2 Crystal structure of $\left[\mathrm{LUO}_{2}(\mathrm{OMe})\right]^{3-}$ (30\% probability) without hydrogen atoms. Up: structure of $\left[\mathrm{K}_{2} \mathbf{L U O}_{2}(\mathrm{OMe})\right]$; down: side view of $\left[\mathrm{LUO}_{2}(\mathrm{OMe})\right]^{3-}$.

Addition of a slight excess of $\mathrm{KOH}$ into a $\mathrm{MeOH}$ solution of $\left[\mathrm{Et}_{3} \mathrm{NH}\right]_{2}\left[\mathbf{L U O}_{2}\right] \cdot 2 \mathrm{H}_{2} \mathrm{O}$ causes an immediate color change from brown to bright red. The ${ }^{1} \mathrm{H}$ NMR spectrum showed the appearance of a methoxide ligand at $5.54 \mathrm{ppm}$. In addition, the 
amide proton signals suggested the presence of multiple species. $\dagger$ These observations indicate that the dominant species is the uranyl methoxide and that the methoxide ligand forms an equilibrium with other molecules, such as $\mathrm{MeOH}$ or DMSO, in solution.

By using a combination of $\mathrm{K}^{+}$and $\mathrm{Me}_{4} \mathrm{~N}^{+}$ions, large dark red crystals of $\left[\mathrm{Me}_{4} \mathrm{~N}\right] \mathrm{K}_{2}\left[\mathbf{L U O}_{2}(\mathrm{OMe})\right]$ were obtained. $\left[\mathrm{Me}_{4} \mathrm{~N}\right] \mathrm{K}_{2}\left[\mathbf{L U O}_{2}(\mathrm{OMe})\right]$ crystallizes in space group $P-1$ with two $\left[\mathbf{L U O}_{2}(\mathrm{OMe})\right]^{3-}$ moeities in the asymmetric unit. The $\mathrm{O}_{\text {amide }} \cdots \mathrm{K}^{+} \cdots \mathrm{O}_{\text {oxo }}$ interactions link $\left[\mathbf{L U O}_{2}(\mathrm{OMe})\right]^{3-}$ moieties to form a three dimensional network in the solid state. $\dagger$ Similar $\mathrm{K}^{+} \cdots \mathrm{O}_{\text {oxo }}$ interactions have been observed in the solid state structures of other uranyl complexes. ${ }^{3,22-26}$ Interestingly, one oxo group in $\left[\mathrm{LUO}_{2}(\mathrm{OMe})\right]^{3-}$ shows interactions with two $\mathrm{K}^{+}$ions (2.825(3) and 3.164(2) A), while the other oxo group shows no such interaction. Aside from the association of $\mathrm{K}^{+}$ions, the most striking differences between $\left[\mathbf{L U O}_{2}(\mathrm{OMe})\right]^{3-}$ and $\left[\mathbf{L}\left(\mathrm{UO}_{2}\right)\right]_{4}{ }^{8-}$ are the coordination mode of $\mathbf{L}$ and the fifth ligand of $\mathrm{UO}_{2}{ }^{2+}$. In $\left[\mathbf{L U O}_{2}(\mathrm{OMe})\right]^{3-}$, the two MeTAM units of $\mathbf{L}$ are coordinated to one $\mathrm{UO}_{2}{ }^{2+}$ ion (Fig. 2) with a methoxide ligand occupying the fifth position. The dramatically different coordination mode of $\mathbf{L}$ is most likely due to the combined effects of the methoxide ligand and $\mathrm{K}^{+}$ions. The methoxide ligand is a much stronger donor $(\mathrm{U}-\mathrm{O}(3)=2.288(3) \AA)^{27}$ than the amide oxygen and its coordination makes the second MeTAM unit free of distortion. In addition, interactions of the $\mathrm{K}^{+}$ion (K2) with both the backbone oxygen (O10) and the uranyl oxo group (O1) bring the second MeTAM unit within the vicinity of uranyl ion, to which the first MeTAM unit of $\mathbf{L}$ has also been bound.

As shown in Fig. 2, $\left[\mathrm{LUO}_{2}(\mathrm{OMe})\right]^{3-}$ shows a rather ruffled structure with large torsion angles $\left(25.4(2)\right.$ to $\left.33.7(2)^{\circ}\right)$ between the MeTAM planes and the corresponding O-U-O planes. The bent binding of the MeTAM units is partially due to the length of the $5 \mathrm{LiO}$ backbone, since a similarly ruffled structure with bent HOPO binding was observed in the 5Li-(Me-3,2-HOPO) uranyl complex. ${ }^{15}$ The $\mathrm{K}^{+} \cdots \mathrm{O}_{\text {phenolate }}$ interactions further contribute to the bending because the torsion angles mentioned above are always larger for the MeTAM unit with $\mathrm{K}^{+} \cdots \mathrm{O}_{\text {phenolate }}$ interactions than those without in $\left[\mathrm{LUO}_{2}(\mathrm{OMe})\right]^{3-}$. The sums of the equatorial angles $\left(360.4(2)\right.$ and $\left.360.3(2)^{\circ}\right)$ are close to $360^{\circ}$ and the mean deviation of the equatorial atoms from the equatorial planes is $c a$. $0.065 \AA$, suggesting a similarly good planar geometry around $\mathrm{UO}_{2}{ }^{2+}$ as the tetramer. Due to the presence of $\mathrm{K}^{+} \cdots \mathrm{O}(1)$ interaction, the $\mathrm{U}-\mathrm{O}(1)$ distance is $c a$. $0.01 \AA$ longer than the corresponding $\mathrm{U}-\mathrm{O}(2)$ distance. The $\mathrm{U}-\mathrm{O}_{\text {phenolate }}$ distances (2.350(2) to 2.412(2) $\AA$ ) and the MeTAM bite angles (65.81(8) to $\left.66.44(8)^{\circ}\right)$ are similar to those in $\left[\mathrm{LUO}_{2}\right]_{4}{ }^{8-}$ (see above). The remaining three equatorial angles in $\left[\mathrm{LUO}_{2}(\mathrm{OMe})\right]^{3-}$ are in the narrow range of $65.81(8)$ to $78.02(9)^{\circ}$, which are considerably closer to $75.7^{\circ}$ than those in the $5 \mathrm{Li}$ or $m$-xyl-(Me-3,2-HOPO) uranyl complexes, ${ }^{15}, 16$ indicating a much more relaxed coordination environment around $\mathrm{UO}_{2}{ }^{2+}$ in $\left[\mathrm{LUO}_{2}(\mathrm{OMe})\right]^{3-}$ than those in the Me-3,2-HOPO complexes. $\dagger$

In summary, we have synthesized and structurally characterized the uranyl complexes of a bis-MeTAM ligand for the first time. Structural analysis of $\left[\mathbf{L}\left(\mathrm{UO}_{2}\right)\right]_{4}{ }^{8-}$ shows that the tetramer formation is governed by the highly relaxed and planar coordination geometry around $\mathrm{UO}_{2}{ }^{2+}$. The corresponding uranyl methoxide complex forms a monomeric salt structure with inclusion of a methoxide ligand. The results presented highlight the effect of uranyl coordination geometry in the molecular structures and will provide information for the design of uranyl sequestering agents based on the TAM unit.

We thank Tiffany A. Pham and Drs. Géza Szigethy, Ga-lai Law, and Christopher M. Andolina for help and discussions. This research is supported by the Director, Office of Science, Office of Basic Energy Sciences, and the Division of Chemical Sciences, Geosciences, and Biosciences of the U.S. Department of Energy at LBNL under Contract No. DE-AC02-05CH11231.

\section{Notes and references}

${ }^{a}$ Chemical Science Division, Lawrence Berkeley National Laboratory ${ }^{b}$ Department of Chemistry, University of California, Berkeley, CA, 94720, USA. E-mail: raymond@socrates.berkeley.edu; Tel:+1 510-642-7219; Fax: +1 510-486-5283.

† Electronic Supplementary Information (ESI) available: Experimental details. CCDC XXXX. For ESI and crystallographic data in CIF or other electronic format, see DOI: 10.1039/b000000x/

1. Part $\mathrm{XX}$ in the series "Specific Sequestering Agents for the Actinides." For Part XX, see reference 18.

2. J. G. Hamilton, Reviews of Modern Physics, 1948, $20,718$.

3. S. Fortier and T. W. Hayton, Coord. Chem. Rev., 2010, 254, 197.

4. N. N. Greenwood and A. Earnshaw, Chemistry of the Elements, Pergamon Presss, New York, 1997.

5. T. Bailly, R. Burgada, T. Prange and M. Lecouvey, Tetrahedron Lett., 2003, 44, 189.

6. G. Y. Xu, C. H. Yang, B. Liu, X. H. Wu and Y. Y. Xie, Heteroat. Chem, 2004, 15, 251.

7. M. Sawicki, J. M. Siaugue, C. Jacopin, C. Moulin, T. Bailly, R. Burgada, S. Meunier, P. Baret, J. L. Pierre and F. Taran, Chem.-Eur. J., 2005, 11, 3689.

8. R. Burgada, T. Bailly, T. Prange and M. Lecouvey, Tetrahedron Lett., 2007, 48, 2315.

9. A. E. V. Gorden, J. D. Xu, K. N. Raymond and P. Durbin, Chem. Rev., 2003, 103, 4207.

10. A. Leydier, D. Lecercle, S. Pellet-Rostaing, A. Favre-Reguillon, F. Taran and M. Lemaire, Tetrahedron, 2008, 64, 6662.

11. A. Leydier, D. Lecercle, S. Pellet-Rostaing, A. Favre-Reguillon, F. Taran and M. Lemaire, Tetrahedron, 2008, 64, 11319.

12. P. W. Durbin, B. Kullgren, J. Xu and K. N. Raymond, Radiat. Prot. Dosim., 1994, 53, 305.

13. P. W. Durbin, B. Kullgren, J. D. Xu and K. N. Raymond, Health Phys., 1997, 72, 865.

14. P. W. Durbin, B. Kullgren, S. N. Ebbe, J. D. Xu and K. N. Raymond, Health Phys., 2000, 78, 511.

15. J. D. Xu and K. N. Raymond, Inorg. Chem., 1999, 38, 308.

16. G. Szigethy and K. N. Raymond, Inorg. Chem., 2010, 49, 6755.

17. G. Szigethy and K. N. Raymond, Inorg. Chem., 2009, 48, 11489.

18. G. Szigethy and K. N. Raymond, Chem. Eur. J., 2011, 17, 1818.

19. P. Thuery and B. Masci, Supramol. Chem., 2003, 15, 95.

20. J. Casellato, P. A. Vigato, S. Tamburini, R. Graziani and M. Vidali, Inorg. Chim. Acta, 1983, 72, 141.

21. S. R. Sofen, K. Abudari, D. P. Freyberg and K. N. Raymond, J. Am. Chem. Soc., 1978, 100, 7882.

22. C. J. Burns, D. L. Clark, R. J. Donohoe, P. B. Duval, B. L. Scott and C. D. Tait, Inorg. Chem., 2000, 39, 5464.

23. J. A. Danis, M. R. Lin, B. L. Scott, B. W. Eichhorn and W. H. Runde, Inorg. Chem., 2001, 40, 3389.

24. P. Thuery and B. Masci, Dalton Trans., 2003, 2411.

25. P. L. Arnold, A. J. Blake, C. Wilson and J. B. Love, Inorg. Chem., 2004, 43, 8206.

26. P. L. Arnold, D. Patel, A. J. Blake, C. Wilson and J. B. Love, J. Am. Chem. Soc., 2006, 128, 9610.

27. I. G. Santos and U. Abram, Inorg. Chem. Commun., 2004, 7, 440. 